\title{
Supracondylar fracture of the humerus with ipsilateral fracture of the scaphoid in a child
}

\author{
M Nashi, B Manjunath, R D Banerjee, R J Creedon
}

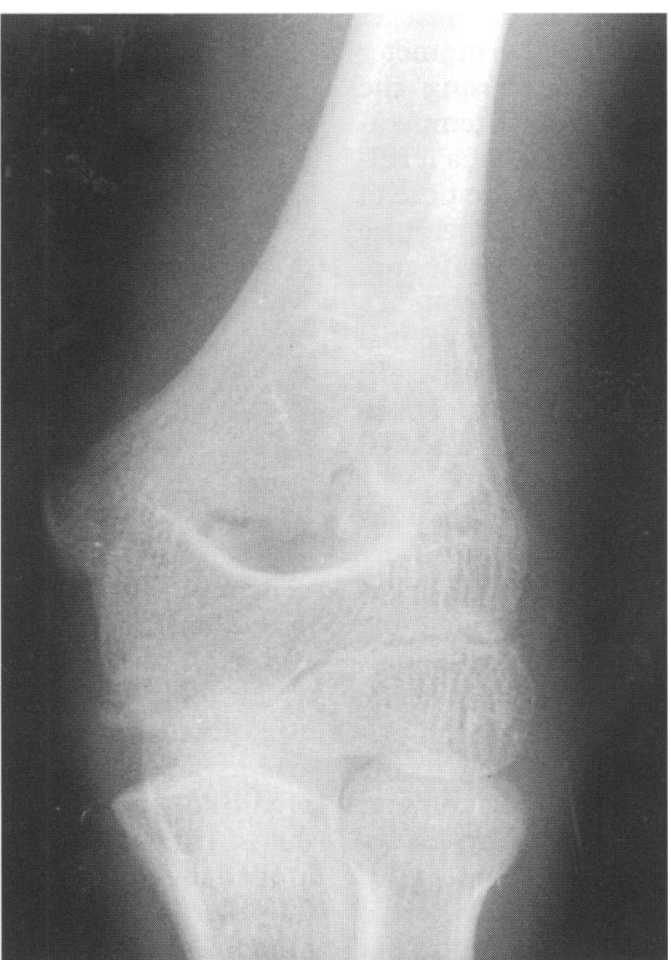

Figure 1 Radiograph of the left elbow demonstrating undisplaced supracondylar fracture of the humerus.

An 11 year old boy fell off a swing onto an outstretched left hand. He attended the accident and emergency department with a painful, swollen left elbow. Radiography of the injured elbow confirmed the undisplaced supracondylar fracture (fig 1). He was treated with a broad arm sling.

A week later the child was seen in the fracture clinic and overall evaluation revealed tenderness over the left scaphoid. Radiography of the wrist confirmed fracture of the waist of the scaphoid (fig 2). He was treated in an above elbow scaphoid cast for three weeks followed by short arm scaphoid cast for another three weeks. When evaluated at four months, both fractures united with an excellent functional result.

Characteristically, supracondylar fracture of the humerus is seen in the first decade of life while fracture of the scaphoid is a rare injury in children due to a relatively thick layer of cartilage surrounding carpal bones. ${ }^{1}$

Supracondylar fractures are often isolated injuries, but they can be associated with ipsilateral fractures particularly of the midshaft and distal forearms. ${ }^{2}$ Carpal injuries in association with other ipsilateral fractures have been rarely

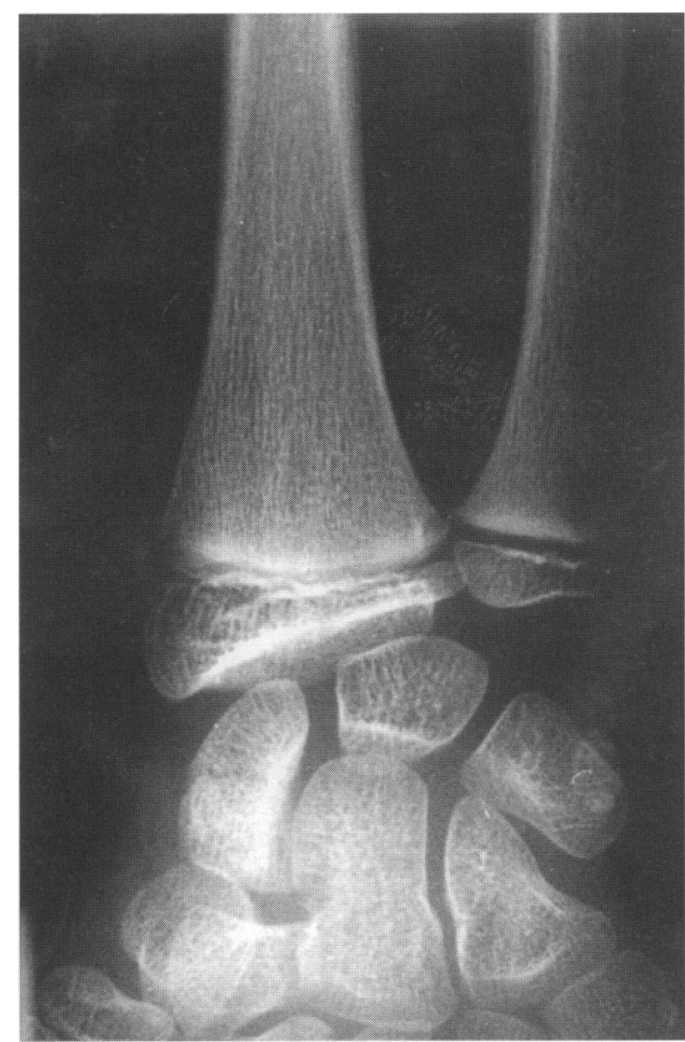

Figure 2 Radiography of ipsilateral wrist demonstrating fracture waist of scaphoid.

reported. Usually severe trauma is required to cause this pattern of injury. ${ }^{3}$ These associated injuries can be overlooked because the severity of pain and deformity at the elbow distract both the patient and physician. ${ }^{4}$

Each of these fractures requires its own individual type of management but if required, the supracondylar fracture should be stabilised first. ${ }^{1}$ Although injuries involving two or more joints in the upper limb are uncommon, this report is aimed at increasing the awareness of the occurrence of such pattern of injuries and that overall assessment by careful physical examination and radiological evaluation avoids overlooking these associated injuries.

1 Rockwood CA Jr, Wilkins KE, King RE. Fractures in children. Vol 3. 3rd Ed. Philadelphia: JB Lippincott, 1991: 372.

2 Minkowitz B, Busch MT. Supracondylar humerus fracture, current trends and controversies. Orthop Clin North Am 1994;25:581-94.

3 Stanitski CL, Micheli LS. Simultaneous ipsilateral fractures of the arm and forearm in children. Clin.Orthop 1980;153: $218-21$.

4 Williamson DM, Cole WG. Treatment of ipsilateral supracondylar and forearm fractures in children. Injury 1992;23:159-61. 